\title{
Farmer Knowledge of Climate Change Impacts and Adaptation Strategies in the Management of Vegetable Insect Pests in Zimbabwe
}

\author{
Rumbidzai D. Katsaruware-Chapoto ${ }^{1,2}$, Paramu L. Mafongoya ${ }^{1} \&$ Augustine Gubba ${ }^{1}$ \\ 1 School of Agricultural, Earth and Environmental Sciences, University of KwaZulu-Natal, Scottsville, \\ Pietermaritzburg, South Africa \\ ${ }^{2}$ Faculty of Agriculture, Zimbabwe Open University, Mashonaland West Region, Chinhoyi, Zimbabwe \\ Correspondence: Rumbidzai D. Katsaruware-Chapoto, Faculty of Agriculture, Zimbabwe Open University, \\ Mashonaland West Region, P.O. Box 285, Chinhoyi, Zimbabwe. Tel: 263-733-831-052. E-mail: \\ rdkatsaruware@gmail.com
}

Received: April 5, 2017 Accepted: July 19, $2017 \quad$ Online Published: November 15, 2017

doi:10.5539/jas.v9n12p194 URL: https://doi.org/10.5539/jas.v9n12p194

The research is financed by National Research Foundation of South Africa (NRF-SA).

\begin{abstract}
Farmer knowledge of insect pests' risks in a changing climate is important in managing insect pests' incidence. A total of 250 vegetable farmers from 5 wards in Zimbabwe were sampled using a semi-structured questionnaire to assess their knowledge on climate change risk, its impact on vegetable insects pests and management strategies to reduce the increased incidence of insect pests. Focus group discussions, key informant interviews and field observations were also used. Droughts and elevated temperatures were perceived to have the greatest impact on vegetable insect pests resulting in their increased incidence. Aphids, cutworms and whiteflies were identified among the major pests that have increased. The majority (53\%) of the farmers cited high vegetable losses from insect pests attack. All the respondents $(100 \%)$ revealed the use of chemical insecticides during production of vegetables. A higher proportion (60\%) perceived effective control, $34 \%$ perceived reduced efficacy and $6 \%$ were not sure of effectiveness of chemical insecticides. Management strategies to cope with the increasing insect pests and diseases on vegetable production also included planting insect resistant cultivars, certified seeds, increased frequency of application of synthetic insecticides, insecticide mixtures, use of more hazardous chemical insecticides and increasing the rates of application resulting in insecticide overuse. There is need for government to facilitate development and adoption of Integrated Insect Pest Management (IIPM) and raise awareness on avoiding overdependence on chemical insecticides. Modelling tools that support adaptation planning needs to be developed to forecast climate change risk and the resultant incidence of insect pests.
\end{abstract}

Keywords: adaptation, elevated temperature, insecticide overuse, knowledge

\section{Introduction}

Climate change and variability has caused devastating effects in both developing and developed countries of the world (IPCC, 2014). Zimbabwe is one of the countries in the sub Saharan region that is prone to the adverse effects of climate change, with predicted increases in mean temperatures, rainfall variability, and an expected increase in extreme weather events such as droughts and flash floods (Rurinda et al., 2014). According to the Zimbabwe Meteorological Service, daily minimum and maximum temperatures have risen by more than $2{ }^{\circ} \mathrm{C}$ over the last century (Brown et al., 2012). Climate records show that temperatures have been increasing by around $0.1{ }^{\circ} \mathrm{C}$ a decade and future scenarios predict increasing temperatures of around $2.5{ }^{\circ} \mathrm{C}$ by the year 2050 (Government of Zimbabwe, 2013). In Zimbabwe, smallholder farmers are vulnerable to the impacts of a changing climate because of multiple factors, such as soil degradation (Rufino et al., 2013) extreme poverty and deterioration of societal 'safety nets' (Antwi-Agyei et al., 2012; Mapfumo et al., 2013). In addition, a dwindling natural resource base (Mapfumo et al., 2013; Rufino et al., 2013) and over dependence on rain fed agriculture also increase the vulnerability of smallholder farmers (IFAD, 2010).

Climate change affects crop yields and hence food security both directly and indirectly (Lobell, 2012). Food security is affected directly through yield losses due to adverse environmental conditions (Mapfumo et al., 2013) 
and indirectly through the changes to the population dynamics and geographic distributions of crop pests (Khan et al., 2014). Insect pest species result in crop losses of about $13.6 \%$ of global agricultural production (Dhaliwal et al., 2010). In Zimbabwe, several studies have been conducted linking climate change with farmer vulnerability (Moyo et al., 2012; Mtambanengwe et al., 2012; Mucharia, 2012). However, these studies have only focused mainly on farmer knowledge of cereal yields such as maize (Mapfumo et al., 2013; Rurinda et al., 2014), but have not incorporated farmer knowledge on vegetable insects pests and farmer management practices considering the importance of vegetable crops nutritionally and economically. Most vegetable crops are grown in agro-ecological zones which are different from their regions of origin, therefore, they are more susceptible to adverse bioclimatic factors and the associated losses (S. Singh \& D. R. Singh, 2013). There is thus a gap in assessing smallholder farmer's knowledge and management of insect pests under a changing climate (Adam et al., 2015).

An understanding of the farmer's knowledge of climate risk is important because it is a prerequisite for adaptation strategies that can be employed to reduce vulnerability to climate change (Sarr et al., 2015). Adaptation measures are of critical importance because the weather patterns have already changed and the changes are expected to continue even if mitigation measures are immediately put into place (Cobon et al., 2009). Without adaptation strategies, climate change is very undesirable to the agricultural sector, but with adaptation, vulnerability can be greatly reduced (Jiri et al., 2015). Farmers' knowledge and management practices may, therefore provide essential information for successful development of successful future pest management strategies (Kihupi et al., 2015).

This study focused on the concepts of knowledge and practices, which have been previously used in some studies in developing countries (Adam et al., 2015; Khan et al., 2015). Since adaptation is key for improving food security (Kihupi et al., 2015; Ramirez-Villegas \& Thornton, 2015), there is need to identify adaptation strategies in the management of insect pests by the smallholder farmers in a changing and variable climate and hence improve food security. The research will be of importance in identifying sustainable solutions to agricultural production constraints by incorporating farmer views into research for development of food security programmes (Okonya et al., 2013). In Zimbabwe, there are five distinct agro ecological regions which imply that there may be different insect pests which are found in these agro ecological regions as well as different management strategies to insect pest management depending on the farmers' agro ecological region. It is against this background that the study was conducted to examine smallholder farmers' knowledge with regard to insect pests of vegetables in a changing climate and the adjustments to insect pest management practices to minimise vegetable losses.

\section{Materials and Methods}

\subsection{Description of Study Area}

The study was conducted in five wards which represented 5 different agro ecological regions also known as natural regions (NR) based on rainfall regime, temperature and soil quality among other factors (Vincent \& Thomas, 1960). The quality of the land resource declines from NR 1 through to NR 5 (Moyo, 2000). These five wards were located in Chipinge, Goromonzi, Mutoko, Masvingo and Chiredzi districts. The ward which produces most vegetables in each agro ecological region was randomly selected for this research. These were Gwayagwaya ward in Chipinge district (NR1; 1118 metres above sea level, masl, greater than $1000 \mathrm{~mm}$ annual rainfall), Munyawiri ward in Goromonzi district (NR2; 1515 masl, 750-1000 mm annual rainfall), Mawanga ward in Mutoko district (NR3; 1168 masl, 650-750 mm annual rainfall), Zimuto ward in Masvingo district (NR4; 1166 masl, 450-650 mm annual rainfall) and lastly Chilonga ward in Chiredzi district (NR5; 485 masl, less than $450 \mathrm{~mm}$ annual rainfall).

\subsection{Survey Design}

This research study employed a mixed methods approach where individual farmers in selected households were the principal units of observation. Mixed methods integrate both quantitative and qualitative research techniques, into a single study therefore enabling a deeper understanding of the subject (Johnson \& Onwuegbuzie, 2004). Data collection was accomplished using a semi-structured survey questionnaire (Blandford, 2013), focus group discussions (Freitas et al., 1998) and field observations. A survey data set containing detailed quantitative data from 250 households from the five agro-ecological regions of Zimbabwe was used. The strata that were used in this research were the agro ecological regions. The respondents were purposively selected based on merit of vegetable production as perceived by the district agriculture extension officers (AREX) and those farmers who have stayed in the area for more than thirty years. 


\subsection{Sampling Procedures}

The procedure for selecting the sampled households involved three stages. In the first stage, a list of wards actively participating in vegetable production was identified from the five agro ecological regions. In the second stage, one ward was randomly selected. Each ward was composed of approximately 500 smallholder farmers. From the randomly selected ward, a $10 \%$ sample size was used to come up with 50 farmers per ward. Five villages from each ward that were perceived by the extension officers as to be more active in vegetable production were identified and selected. In the final stage, 10 households from each of the 5 villages were then randomly selected for the purpose of this study.

\subsection{Pretesting of the Questionnaire}

Pretesting of the survey questionnaire was done on five households in each agro ecological region where farmers were not surveyed. Pre-testing of the questionnaire was done to get used to the data collection exercise, enable a better understanding of the subject being investigated, to help the researchers to practice the interviewing technique, to provide the researchers with the opportunity to probe relevant responses from the focus group participants as well as to identify and address shortcomings of the questionnaire. After pretesting of the questionnaire, changes were made in the expression of some questions to be asked.

Agricultural extension (AGRITEX) enumerators that were conversant with the study areas were hired to conduct the household interviews during the field research. Before the surveys were conducted, enumerators received field training on the survey instruments and ethical considerations of this research. To minimize bias, questions were interactive and farmers were allowed to indicate other answers in case the stated options did not meet their responses. This technique was useful in exploring the responses of the farmers to gather more and deeper information on the subject.

In addition to the survey questionnaire, three focus groups meetings were held in each district whereby each group was composed of 16 farmers. The focus group discussions were carried out with the anticipation of a wider range of responses from group responses thereby allowing participants to build on each other's ideas and comments. Knowledge, in this context, refers to what farmers know about the problem of vegetable pests that are responding to a changing climate while management practices refer to the actual actions that farmers take to control the insect pests. Information was collected on climate induced risks affecting insect pests in vegetable production, the corresponding vegetables affected, the status of natural enemies, an estimate of crop yield losses as a result of insect pest attack and the various management practices to reduce insect pest hazard in a changing climate. On natural enemies, photographs were also used for the correct identification of natural enemies that prey upon some common insects in the country.

\subsection{Statistics and Data Analysis}

The data was subjected to a one-way analysis of variance ANOVA at $\mathrm{P}<0.05$ to assess any differences between agro-ecological zones and the farmer's responses using SPSS version 16. At $\mathrm{P}<0.05$, a Post Hoc Multiple comparison was used to determine the agro ecological regions that exhibited significant differences. Descriptive statistics such as frequencies, percentages and ranking were also used in the study.

\section{Results}

\subsection{Major Climate Induced Challenges to Vegetable Production}

The survey results revealed that across all the agro ecological regions, there was were no significant differences on the challenges that are encountered by farmers in vegetable production. Overall, the majority $(40.8 \%)$ of the respondents cited droughts and a corresponding inadequate irrigation water as a major challenge to vegetable production. Insects, plant diseases and weeds were cited by $24 \%, 24 \%$ and $11.2 \%$ of the total respondents respectively. This implies that the various challenges that affect vegetable production were independent of the agro ecological region in which the farmers were located, but were uniform across the various agro ecological regions.

\subsection{Extent of Crop Losses from Insect Pests and Disease Attack}

In terms of crop losses attributable to insect pest attack across the agro ecological regions, fifty three percent reported high vegetable losses, $27 \%$ indicated that the losses from insects and diseases were moderate and $20 \%$ indicated that losses due to insects and diseases were low. However there were significant differences $(\mathrm{P}<0.05)$ on the extent of crop losses between the agro ecological regions. The extent of vegetable losses in natural regions 1,2 and 3 were not significantly different from each other but they were significantly higher compared to extent of vegetable losses encountered in natural regions 4 and 5 (Table 1). This shows that the major vegetable 
producing regions were affected more by insect pest attack than the agro ecological regions where vegetables are produced on a much smaller scale.

Table 1. Extent of crop losses from insect pests ( $\%$ responses; $\mathrm{N}=250$ )

\begin{tabular}{llllllll}
\hline Variable & NR1 & NR2 & NR3 & NR4 & NR5 & Mean \% & P-value \\
\hline High & 52 & 72 & 76 & 34 & 32 & 53 & $0.00^{*}$ \\
Moderate & 38 & 10 & 10 & 42 & 34 & 27 & $*$ \\
Low & 10 & 18 & 14 & 24 & 34 & 20 & $*$ \\
Total & 100 & 100 & 100 & 100 & 100 & 100 & \\
\hline
\end{tabular}

Note. Values in the tables indicate percentages, $\mathrm{P}<0.05$ shows there was a significant difference, ${ }^{*}$ indicates highly significant at $\mathrm{P}<0.01$.

\subsection{Farmer Ranking of Major Vegetable Insect Pests}

Using the problem ranking matrix, the study showed that the top three insect pests that mostly affected vegetable production across all the agro ecological regions were aphids which were cited by all $(100 \%)$ of the respondents, cutworms cited by $98 \%$ and whiteflies which were cited by $86 \%$. However armyworm were the least cited insect pests with a fewer respondents (31\%) compared to the other insect pests (Table 2).

Table 2. Farmer ranking of major vegetable insect pests on a scale from 1 (most serious) to 10 (least serious) (\% responses; $\mathrm{N}=250$ )

\begin{tabular}{llllllll}
\hline Insect & NR1 & NR2 & NR3 & NR4 & NR5 & $\%$ & Ranking \\
\hline Cabbage Loopers & 66 & 80 & 60 & 40 & 24 & 54 & 6 \\
Aphids & 100 & 100 & 100 & 100 & 100 & 100 & 1 \\
Whiteflies & 92 & 96 & 84 & 82 & 76 & 86 & 3 \\
Beetles & 48 & 38 & 26 & 42 & 14 & 34 & 9 \\
Leaf miners & 84 & 92 & 98 & 40 & 44 & 72 & 5 \\
Fruit flies & 64 & 42 & 60 & 26 & 18 & 42 & 8 \\
Diamond Back Moth & 82 & 100 & 100 & 60 & 76 & 84 & 4 \\
Thrips & 74 & 80 & 60 & 26 & 20 & 52 & 7 \\
Cut worms & 100 & 100 & 100 & 86 & 84 & 98 & 2 \\
Armyworm & 33 & 40 & 38 & 23 & 20 & 31 & 10 \\
\hline
\end{tabular}

Note. Total percentages within the table columns exceed $100 \%$ due to multiple responses.

Source: Survey data (2015).

In the focus group discussions, aphids were cited by the majority of the farmers as the discussants highlighted that the pest feed on a wide range of field crops, vegetables, ranging from the brassicas (rape, cabbages, mustard), solanaceous (tomatoes, potatoes), cucurbits (squashes) and other vegetables. The diamond back moth was cited as an important insect pest amongst the leafy vegetables such as rape, kale, cabbage and cauliflower. Farmers noted that most of the damage caused by the insect pests resulted in destruction of the vegetable foliage, stunted growth, reduction in the quality of leafy vegetables and hence death of the plants. However the majority of the farmers were not aware of the ability of the insect pests to transmit plant diseases, although from our field observations, there were disease like symptoms which were evidenced by the mosaic pattern on aphid infested vegetables such as the tomatoes.

\subsection{The Frequency of Spraying and Effectiveness of Synthetic Insecticides}

Across the five agro-ecological regions, all the respondents interviewed indicated that they spray chemical insecticides to manage insect pests at some point during the production cycle of vegetables. There was no significant difference $(\mathrm{P}>0.05)$ in the frequency of spraying insecticides across the five agro ecological regions. Forty four percent highlighted that they spray vegetables at an average frequency of once per month, while $29 \%$ spray insecticides twice per month and $27 \%$ spray vegetables more than two times per month, indicating a high insecticide use. 
There was a significant difference on the perceived effectiveness of the chemical insecticides within the 5 NR between (NR1, NR2 and NR3) and (NR4 and NR5). There was no significant difference in the effectiveness of the chemical insecticides between NR1, 2 and 3 where the insecticides were was reported to be effective. The responses of farmers in NR1, 2 and 3 were significantly different from those of NR4 and NR5 at $\mathrm{P}<0.05$. The farmers in NR4 and NR5 felt that the chemical insecticides were ineffective. However, across the agro ecological regions, the majority $(60 \%)$ of the farmers highlighted that the chemicals insecticides were effective while $34 \%$ felt that some insecticides were ineffective and $6 \%$ had mixed feelings on the effectiveness of the chemical insecticides.

\subsection{Farmer Choice of Synthetic Insecticides Used in Insect Pest Management}

In the focus group discussions, management of the perceived increasing insect pests' incidence mainly involved the use of various chemical insecticides which included the synthetic carbamates (carbaryl and aldicarb) and organophosphates (acetamiprid, malathion, diazinon, tamaron, monocrotophos and chlopyriphos). Organochlorines that were used by the farmers include dicofol as well as the pyrethroids such as fenvalerate. However, some farmers use insecticides that are intended for use on non-food crops such as tobacco and cotton (monocrotophos, tamaron) citing that the green labelled chemicals that are intended for use on vegetables such as dimethoate (locally known as rogor) are no longer effective and have resorted to use of red labelled chemicals which are highly toxic. The chemicals that were cited as being effective by the farmers are mainly the chemicals in the high to extreme toxicity group (Table 3).

Table 3. Farmers' choice of the synthetic pesticides used to control vegetable pests in a changing climate and period of high pest incidence

\begin{tabular}{|c|c|c|c|}
\hline Insect pest & Period of high pest incidence & Insecticides & Colour of label \\
\hline \multirow[t]{9}{*}{ Aphids } & All year round & Dimethoate & Green \\
\hline & & Malathion & Green \\
\hline & & Diazinon & Green \\
\hline & & Fenvalerate* & Red \\
\hline & & Chlopyriphos* & Red \\
\hline & & Lambda* & Red \\
\hline & & Tamaron* & Red \\
\hline & & Dithane M45 & Green \\
\hline & & Monocrotophos* & Red \\
\hline \multirow[t]{3}{*}{ Whiteflies } & Hot season & Fenvalerate & Red \\
\hline & & Malathion & Green \\
\hline & & Diazinon & Green \\
\hline \multirow[t]{2}{*}{ Leaf miners } & Hot season & Monocrotophos* & Red \\
\hline & & Carbaryl & Amber \\
\hline \multirow[t]{3}{*}{$\mathrm{DBM}$} & All year round & Diazinon* & Green \\
\hline & & Carbaryl* & Amber \\
\hline & & Malathion & Green \\
\hline Thrips & Hot season & Malathion & Green \\
\hline \multirow[t]{2}{*}{ Cutworms } & All year round & Chlopyriphos & Red \\
\hline & & Lambda & Red \\
\hline Leaf hopper & Hot season & Carbaryl & Amber \\
\hline Grasshopper & Hot season & Carbaryl & Amber \\
\hline $\mathrm{CL}$ & Warm weather & Carbaryl & Amber \\
\hline
\end{tabular}

Note. CL: Cabbage looper; *Indicates an insecticide that is not registered for use on a particular pest in vegetables.

Source: Focus group discussions (2015).

In the focus group discussions, the majority of the discussants did not know the role that is played by natural enemies in the control of insect pests. However, the natural enemy that the farmers knew was the lady bird beetle 
and it was believed that its population had declined. However from our observations, the fields that were frequently sprayed (sprayed for at least twice per month) with chemical insecticides had no signs of any natural enemy compared to fields that were sprayed less frequently (once per month) which hosted some ladybird beetles.

\subsection{Other Insect Pest Management Strategies Used by Farmers}

There was no significant difference $(\mathrm{P}>0.05)$ on the type of insect pest management strategy that was implemented by the farmers across the five agro ecological regions. In all the agro ecological regions the majority $(28.8 \%)$ of the farmers intercrop vegetables with other plants (e.g. kale intercropped with onions or garlic). This was followed by the use of chemical mixtures which was practised by $25.2 \%$ of the respondents. Trap cropping was practised by $20.4 \%$ while $5.6 \%$ removed plants that were severely infested with insect pests from the fields and $20 \%$ rotated vegetables for insect pest control. In the focus group discussions, the farmers highlighted that they have adopted traditional measures from the use of plant extracts such as using the apple of Peru (Nicandra physalodes), chilli extracts (Capsicum annum), garlic (Allium sativum) extracts, increasing diversity of vegetable crops within fields, reduction in the size of land that is under vegetable production, location of vegetable gardens near homesteads where they can constantly monitor insect pests and take appropriate control measures. Regular weeding in and around vegetable gardens was also highlighted by the farmers as one of the measures of controlling insect pests as the weeds were indicated to harbour some insect pests which would migrate easily to the adjacent vegetable crops.

\section{Discussion}

The majority of the farmers in this study were aware of the climate induced challenges to crop production. This was similar to studies that were carried out in Uganda (Okonya et al., 2013). Climatic factors affected vegetable production leading to low yield because vegetables crops are very sensitive to environmental extremes, and therefore high temperatures and limited soil moisture exacerbated by climate change directly though yield losses and indirectly through increases in insect pest incidence reduce productivity in the tropical regions (S. Singh \& D. R. Singh, 2013; Singh \& Bainsia, 2015).

The majority of the studies that were conducted in several African countries showed that insect pests are some of the greatest challenges to vegetable production in an environment of a changing climate (Emana et al., 2015; Midega et al., 2013). This was also in line with the observation of Munthali and Tshegofatso (2013) and Norman et al. (2014) in Botswana and Sierra Leone respectively who indicated that the majority of the farmers surveyed associated vegetable yield loss to insect pests attack under warming climate conditions. In a related research that was carried out in Tamil Nadu in India, farmers perceived insect pests as the most critical bioclimatic challenge resulting in $65-70 \%$ of vegetable loss as a result of the destructive activities of insect pests such as the fruit borers, whiteflies and thrips (Schreinemachers et al., 2015). This suggests that much of the damage on vegetables and related losses were attributed to insect pests attack whose populations and hence destructive activities are magnified by a warming climate.

The farmers reported an increase in insect pest abundance in a changing climate with the top three insect pests being the aphids, cutworms and the whiteflies. Aphids being more abundant under warm conditions, are also found on the growing points of vegetables therefore making them more visible to the farmer. Cutworm was ranked as another important insect pest of vegetables because their early arrival in the life cycle of vegetables and their cutting down of tender plants make them more easily noticeable by the farmers (Okonya \& Kroschel, 2015).

The use of chemical insecticides by all the respondents across the agro-ecological regions as a result of their effectiveness was in line with a study that was carried out in Thailand, Vietnam, India and Pakistan which showed that all the smallholder farmers in these four Asian countries relied heavily on synthetic pesticides to control insects' pests (Khan \& Damalas, 2015; Schreinemachers et al., 2015). In Pakistan, Punjab district where crops are produced, all the farmers surveyed reported using insecticides extensively as the only effective way of controlling pests (Khan \& Damalas, 2015; Khan et al., 2015). The perceived reduced efficacy of some insecticides such as dimethoate could also have been due to some extreme temperatures in NR4 and NR5 which degrades most organophosphates thereby rendering many of the chemical insecticide products to be less effective in a warming climate (Musser \& Shelton, 2005). In addition, the increase in insect pests as a result of a warming climate could also have led to increased use of chemical insecticides among the farmers (FAO, 2006) This might have led to insecticide resistance due to continuous use of synthetic insecticides (Fand et al., 2012; Cothran et al., 2013). This however requires further increases in the rates of insecticide application and the use of more hazardous chemical insecticides. The use of the hazardous chemical insecticides were in line with the study of 
Khan et al. (2015) in Pakistan who noticed that $55 \%$ of the smallholder farmers used moderately hazardous while $23 \%$ used highly hazardous chemical insecticides because of their perceived effectiveness compared to the mild insecticides.

Farmers cited reduced effectiveness of natural enemies while others were not sure of the status and role of the natural enemies in insect pest management. This could have been as a result of low knowledge about natural enemies among the smallholder farmers. This was similar to observations that were conducted in Benin (Loko et al., 2013) and Uganda (Okonya \& Kroschel, 2016) which showed that smallholder farmers are not aware of the role that is played by natural enemies. The excessive use of synthetic insecticides could have also eliminated both target and non-target species thereby increasing the susceptibility of natural enemies to insecticides and a corresponding reduction in their populations (Chidawanyika et al., 2012; Selvaraj et al., 2013). In addition to the excessive use of chemical insecticide, the small and delicate nature of most of the natural enemies also makes them susceptible to weather extremes (high temperature, wind and heavy rainfall) which are characteristic of a changing climate thereby resulting in a decline in their populations (Fand et al., 2012; Gerard et al., 2012). In an experimental study that was carried out in Southern California, a $3{ }^{\circ} \mathrm{C}$ increase in average summer temperatures resulted in a reduction in offspring production by about $90 \%$ for an important beneficial wasp (Cotesia marginiventris) (Trumble \& Butler, 2009). This therefore means that with a warming climate, there is most likely to be a reduction in the abundance and activity of natural enemies.

The use of chemical mixtures in this study was similar to the practice of smallholder farmers in Asian countries such as Pakistan and African countries such as Uganda who mix various synthetic insecticides into single sprays in order to effectively control crop pests (Khan \& Damalas, 2015; Okonya \& Kroschel, 2015; Schreinemachers et al., 2015). Insecticide mixtures have a synergistic effect in insect pest control thereby enhancing the effectiveness of insect pest control under warming conditions (Abd El Mageed \& Shalaby, 2011).

Cultural insect pest management practices such as intercropping, removal of heavily infested plants and switching to disease resistant cultivars have also been manipulated by smallholder farmers to manage insect pests. Specialist insect such as the diamond back moth (Plutella xylostella), which only attacks cruciferous crops, is an example of insect pest with a narrow host range which can be managed by intercropping with a crop that belongs to a different family (Smith \& Liburd, 2015). Intercropping a susceptible and a non-susceptible crop control insect pests by interfering with the ability of an insect to detect host plants by the production of volatile chemical compound by the component crop that confuse the insect (Smith \& Liburd, 2015).

Removal of heavily affected plants and the use of pest resistant plant varieties was practiced by sweet potato farmers in Tanzania where $72 \%$ of the farmers in the Mara region removed affected plants from the field while (55\%) stopped growing a variety in their field or got a resistant plant material (Adam et al., 2015). This management strategy reduced the chances of migration of insect pests to adjacent healthy crops or fields (Okonya \& Kroschel, 2016).

Trap cropping in insect pest management results in fewer pests on the main crop than if the trap crop were not present especially in specialist insects which have a narrow host range such as diamond back moths (Zhou et al., 2011). In Florida, a plant of the Brassica family, collard greens (Brassica oleracea var. Acephala L.) has been used as a trap crop to suppress infestations of diamond back moth larvae in cabbages (Mitchell et al., 2000). In an experiment where tobacco was produced, Colocasia esculenta hosted large numbers of the adults of second generation S. litura and provided adult females with an optimal oviposition site, hence the number of egg masses on tobacco was lower in trap cropping than in treatments where the tobacco pest was chemically controlled (Zhou et al., 2011).

Farmer support services such as agricultural extension services increase farmer's knowledge on the risks associated with climate change as well as the management options (ATPS, 2013). Other sources of insect pest management information such NGOs had fewer respondents but were important in the dissemination of pest management information. This was in line with a study that was carried out in Tanzania which showed that apart from farmer extension services as the main source of information, farmers can also acquire information on various farming ideas through other means such as through farming experience and various informal networks (Adam et al., 2015). In a related study that was carried out in Italy, it was shown that apart of agricultural extension, farmers' field days were found to be effective way of communicating risks and adaptation options to a changing climate (Menapace et al., 2015).

\section{Conclusion and Recommendations}

Increasing temperatures, increased abundance of insect pests, plant diseases and weeds have been identified by the farmers as the major challenges to vegetable production under a changing climate with increasing 
populations of insect pests such as the aphids, cutworms and whiteflies across all the natural regions. Chemical insect pest management through application of increased insecticide rates, increased frequency of application and mixing chemical insecticides have been found to be the major strategies that were used by farmers for the management of insect pests in a changing climate resulting in overuse of chemical insecticides. Cultural insect pest management strategies such as intercropping, crop rotation, removal of affected crops and use of trap crops have also been used by farmers to control insect pests. The study revealed that smallholder farmers have little knowledge of the role that is played by natural enemies in the management of insect pest, therefore there is a need to train smallholder farmers or improve their understanding on the identification as well as the role that can be played by natural enemies in insect pest management so as to conserve them. Farmer training on adoption of more environmentally friendly strategies such as Integrated Insect Pest Management (IIPM) to reduce over reliance on chemical insecticides and therefore adapt to increasing insect pest challenges under a changing climate is also of importance. Forewarning models for predicting insect arrival, presence, absence or abundance based on earlier climate profiles will be of importance in order to provide a more precise spatial distribution of insect pests in the various agro ecological regions of Zimbabwe which assists in estimating the potential vulnerability of the farmers.

\section{References}

Abd, E. M., \& Shalaby, S. E. M. (2011). Toxicity and Biochemical Impacts of Some New Insecticide Mixtures on Cotton Leafworm Spodoptera littoralis (Boisd.). Plant Protection Science, 47(4), 166-175.

Adam, R. I., Sindi, K., \& Badstue, L. (2015). Farmers' knowledge, perceptions and management of diseases affecting sweet potatoes in the Lake Victoria zone region, Tanzania. Crop Protection, 72, 97-107. https://doi.org/10.1016/j.cropro.2015.02.010

African Technology Policy Studies Network (ATPS). (2013). Farmers' Response and Adaptation Strategies to Climate Change in Mafeteng District, Lesotho [Tsepo Stephen Tiisetso Sekaleli, Karabo Sebusi]. ATPS Working Paper No. 74.

Antwi-Agyei, P., Fraser, E. D. G., Dougill, A. J., Stringer, L. C., \& Simelton, E. (2012). Mapping the vulnerability of crop production to drought in Ghana using rainfall, yield and socio economic data. Applied Geography, 32, 324-334. https://doi.org/10.1016/j.apgeog.2011.06.010

Blandford, A. (2013). Semi-structured qualitative studies. In M. Soegaard \& R. F. Dam (Eds.), The Encyclopedia of Human-Computer Interaction (2nd ed.). Aarhus, Denmark: The Interaction Design Foundation. Retrieved from http://www.interactiondesign.org/encyclopedia/semi-structured_qualitative_studies.html

Brown, D., Chanakira, R., Chatiza, K., Dhliwayo, M., Dodman, D., Masiiwa, M., .. Mugabe, P. (2012). Climate Change: Climate change impacts, vulnerability and adaptation in Zimbabwe. IIED Working Paper No. 3. Climate Change Group International Institute for Environment and Development.

Chidawanyika, F., Mudavanhu, P., \& Nyamukondiwa, C. (2012). Biologically based methods for pest management in agriculture under changing climates: Challenges and future directions. Insects, 3, 1171-1184. https://doi.org/10.3390/insects3041171

Cobon, D. H., Stone, G. S., Carter, O. J., Scanlan, J. C., Toombs, N, R., Zhang, X., Willocks, J., \& Mckeon, G. M. (2009). The climate risk management matrix for the grazing industry of northern Australia. The Rangeland Journal, 31, 31-49. https://doi.org/10.1071/RJ08069

Cothran, R. D., Brown, J. M., \& Relyea, R. A., (2013). Proximity to agriculture is correlated with pesticide tolerance: Evidence for the evolution of amphibian resistance to modern pesticides. Evolutionary Applications, 6, 832-841. https://doi.org/10.1111/eva.12069

Dhaliwal, G. S., Jindal, V., \& Dhawan, A. K. (2010). Insect pest problems and crop losses: Changing trends. Indian Journal of Ecology, 37, 1-7. https://doi.org/10.5958/0974-8172.2015.00033.4

Emana, B., Afan-Sefa, V., Dinsa, F. F., Ayana, A., Balemi, T., \& Temesgen, M. (2015). Characterization and Assessment of Vegetable Production and Marketing Systems in the Humid Tropics of Ethiopia. Quarterly Journal of International Agriculture, 54(2), 163-187. https://doi.org/10.1186/s40066-016-0085-1

Fand, B. B., Kamble, A. L., \& Kumar, M. (2012). Will climate change pose serious threats to crop pest management: A critical review? International Journal of Science and Research Publications, 2(11), 1-14.

FAO. (2006). Report of the Joint Meeting of the FAO Panel of Experts on Pesticide Residues in Food and the Environment and the WHO Core Assessment Group on Pesticide Residues. Rome, Italy. 
Freitas, H., Oliveira M., Jenkins M., \& Popjoy O. (1998). The Focus Group, a qualitative research method. WP ISRC No. 010298 (p. 22). ISRC, Merrick School of Business, University of Baltimore (MD, EUA).

Gerard, L., Liu, O. L., Corliss, S., Varma, K., Spitulnik, M., \& Linn, M. C. (2012). Teaching with visualizations: A comparison study. In C. Mouza \& N. Lavigne (Eds.), Emerging technologies for the classroom: A learning sciences perspective (pp. 63-80). New York, NY: Springer.

Government of Zimbabwe (GOZ). (2013). Zimbabwe National Climate Change Response Strategy (First Draft). Ministry of Environment and Natural Resources Management, Harare.

IFAD. (2010). Rural Poverty Report 2011-New realities, new challenges: New opportunities for tomorrow's generation. IFAD, Rome.

IPCC. (2014). Impacts, adaptation and vulnerability. Summary for Policymakers. Working Group II Contribution to the 5th Assessment Report of the Intergovernmental Panel on Climate Change.

Jiri, O., Mafongoya, P., \& Chivenge, P. (2015). Smallholder Farmer Perceptions on Climate Change and Variability: A Predisposition for their Subsequent Adaptation Strategies. Journal of Earth Science and Climate Change, 6, 277. https://doi.org/10.4172/2157-7617.1000277

Johnson, R. B., \& Onwuegbuzie, J. A. (2004). Mixed methods research: A research paradigm whose time has come. Educational Research, 33(7), 14-26. https://doi.org/10.3102/0013189X033007014

Khan, M., \& Damalas, C. A. (2015). Factors preventing the adoption of alternatives to chemical pest control among Pakistan cotton farmers. International Journal of pest management, 61, 9-16. https://doi.org/ 10.1080/09670874.2014.984257

Khan, M., Mahmood, H. Z., \& Damalas, C. A. (2015). Pesticide use and risk perceptions among farmers in the cotton belt of Punjab, Pakistan. Crop Protection, 67, 184-190. https://doi.org/10.1016/j.cropro.2014.10.013

Khan, Z. R., Midega, C. A. O., Pittchar, J. O., Murage, A. W., Birkett, M. A., Bruce, T. J. A., \& Pickett, J. A. (2014). Achieving food security for one million sub-Saharan African poor through push-pull innovation by 2020. Philosophical Transactions for the Royal Society of Britain, 369, 20120284. https://doi.org/10.1098/ rstb.2012.0284

Kihupi, N. I., Tarimo, A. K. P. R., Masika, R. J., Boman, B., \& Dick, W. A. (2015). Trend of growing season characteristics of semi-arid Arusha district in Tanzania. Journal of Agricultural Science, 7(9), 45-55. https://doi.org/10.5539/jas.v7n9p45

Lobell, D. B., \& Gourdji, S. M. (2012). The influence of climate change on global crop productivity. Plant productivity. Plant Physiology, 160(4), 1686-1697. https://doi.org/10.1104/pp.112.208298

Loko, Y. L., Dansi, A., Tamo, M., Bokonon-Ganta, A. H., Assogba, P., Dansi, M., ... Sanni, A. (2013). Storage Insects on Yam Chips and Their Traditional Management in Northern Benin. The Scientific World Journal, 2013(6), Article ID 484536. https://doi.org/10.1155/2013/484536

Macharia, P. N., Thuranira, E. G., Ngung'a, L. W., Lugadiru, J., \& Wakori, S. (2012). Perceptions and adaptation to climate change and variability by immigrant farmers in semi-arid regions of Kenya. African Crop Science Journal, 20, 287-296.

Mapfumo, P., Adjei-Nsiah, S., Mtambanengwe, F., Chikowo, R., \& Giller, K. E. (2013). Participatory action research (PAR) as an entry point for supporting climate change adaplation by smallholder farmers in Africa. Environmental Development, 5, 6-22. https://doi.org/10.1016/j.envdev.2012.11.001

Menapace, L., Colson, G., \& Rafaelli, R. (2015). Climate change beliefs and perceptions of agricultural risks: An application of the exchangeability method. Global Environmental Change, 35, 70-81. https://doi.org/ 10.1016/j.gloenvcha.2015.07.005

Midega, C., Pittchar, J., Salifu, D., Pickett, J. A., \& Khan, Z. R. (2013). Effects of mulching, N-fertilization and intercropping with Desmodium uncinatum on Striga hermonthica infestation in maize. Crop Protection, 44, 44-49. https://doi.org/10.1080/09670874.2014.984257

Mitchell, E. R., Hu, G., \& Johanowicz, D. (2000). Management of diamondback moth in cabbage using collard as a trap crop. Horticulture Science, 35, 875-879.

Moyo, M., Mvumi, B. M., Kunzekweguta, M., Mazvimavi, K., Craufurd, P., \& Dorward, P. (2012). Farmer perceptions on climate change and variability in semi-arid Zimbabwe in relation to climatology evidence. African Crop Science Journal, 20(2), 317-335. 
Moyo, S. (Ed.). (2000). Zimbabwe environmental dilemma: Balancing resource inequities. Harare, Zimbabwe Environmental Research Organization.

Mtambanengwe, F., Mapfumo, P., Chikowo, R., \& Chamboko, T. (2012). Climate change and variability: Smallholder farming communities in Zimbabwe potray a varied understanding. African Crop Science Journal, 20(2), 227-241.

Munthali, D. C., \& Tshegofatso, A. B. (2013). Major insect pest attacking okra: Abelmoschus esculentus L. (Moench) in Sebele, Botswana. Botswana Journal Agriculture and Applied Science, 9(2), 90-96.

Musser, F. P., \& Shelton, A. M. (2005). The influence of post-exposure temperature on the toxicity of insecticides to Ostrinia nubilalis (Lepidoptera: Crambidae). Pest Management Science, 61, 508-510. https://doi.org/10.1002/ps.998

Norman, J. E., Kanteh, S. M., Samura, A. E., \& Mansaray, A. (2014). Farmer's knowledge perception and management of key pests of okra (Abelmoschus esculentus) in Southern Sierra Leone. Journal of Harmonised Research in applied Sciences, 2(4), 328-340.

Okonya, J. S., \& Kroschel, J. (2015). A Cross-Sectional Study of Pesticide Use and Knowledge of Smallholder potato Farmers in Uganda. BioMed Research International, 2015, Article ID 759049. https://doi.org/ $10.1155 / 2015 / 759049$

Okonya, J. S., \& Kroschel, J. (2016). Farmers' knowledge and perceptions of potato pests and their Management in Uganda. Journal of Agriculture and Rural Development in the Tropics and Subtropics, 117(1), 87-97.

Okonya, J. S., Mwanga, R. O. M., Syndikus, K., \& Kroschel, J. (2013). Insect pests of sweet potato in Uganda: Farmers' perceptions of their importance and control practices. Springer Plus, 3, 303. https://doi.org/ 10.1186/2193-1801-3-303

Ramirez-Villegas, J., \& Thornton, P. K. (2015). Climate change impacts on African crop production. CCAFS Working Paper No. 119. Copenhagen, Denmark: CGIAR Research Program on Climate Change, Agriculture and Food Security (CCAFS).

Rufino, M., Thornton, P., Ng'ang'a, S., Mutie, I., Jones, P., van Wijk, M., \& Herrero, M. (2013). Transitions in agro-pastoralist systems of East Africa: Impacts on food security and poverty. Agriculture Ecosystem and the Environment, 179, 215-230. https://doi.org/10.1016/j.agee.2013.08.019

Rurinda, J., Mapfumo, P., van Wijk, M. T., Mtambanengwe, F., Chikowo, R., \& Giller, K. E. (2014). Sources of vulnerability to a variable and changing climate among smallholder households in Zimbabwe: A participatory analysis. Climate risk Management, 3, 65-78. https://doi.org/10.1016/j.crm.2014.05.004

Sarr, B., Atta, S., Ly, M., Salack, S., Ourback, T., Subsoil, S., \& George, D. A. (2015). Adapting to climate variability and change in smallholder farming communities: A case of Burkina Faso, Chad and Niger (CVCADAPT). Journal of Agricultural and Extension and Rural Development, 7(1), 16-27. https://doi.org/10.5897/JAERD14.0595

Schreinemachers, P., Balasubramaniam, S., Boopathi, N. M., Cuong, V. H., Lawrence, K., Suwanna, P., ... Mei-Huey, W. (2015). Farmers' perceptions and management of plant viruses in vegetables and legumes in tropical and subtropical Asia. Crop Protection, 75, 115-123. https://doi.org/10.1016/j.cropro.2015.05.012

Singh, S., \& Bainsia, N. K. (2015). Analysis of Climate Change Impacts and their Mitigation Strategies on Vegetable Sector in Tropical Islands of Andaman and Nicobar Islands. Indian Journal of Horticulture, 2, 126. https://doi.org/10.4172/2376-0354.1000126

Singh, S., \& Singh, D. R. (2013). Species diversity of vegetables crops in Andaman and Nicobar Islands: Efforts and challenges for utilization. In D. R. Singh, et al. (Eds.), Souvenir on Innovative technologies for conservation and sustainable utilization of island biodiversity (pp. 121-129). CARI, Port Blair.

Smith, H. A., \& Liburd, O. E. (2015). Intercropping, crop diversity and pest management. IFAS Extension, University of Florida.

Trumble, J. T., \& Butler, C. D. (2009). Climate change will exacerbate California's insect pest problems. California Agriculture, 63(2), 73-78. https://doi.org/10.3733/ca.v063n02p73

Vincent, V., \& Thomas, R. G. (1960). An agricultural survey of Southern Rhodesia: Part I: agro-ecological survey. Government Printer, Salisbury. 
Zhou, Z. S., Xu, Z. F., \& Chen, Z. P. (2011). Co-efficacy of a Trap Crop, Colocasia esculenta (L.) Schott and a Biological Agent, Spodoptera litura Nuclear Polyhedral Virus on the Tobacco Caterpillar, Spodoptera litura (Fabricius) in the Tobacco Field. Pakistan Journal of Zoology, 43(4), 689-699.

\section{Copyrights}

Copyright for this article is retained by the author(s), with first publication rights granted to the journal.

This is an open-access article distributed under the terms and conditions of the Creative Commons Attribution license (http://creativecommons.org/licenses/by/4.0/). 